\title{
Use of Extended Flute Techniques in Flute Education in Turkey
}

\author{
Ajda Şenol Sakin ${ }^{1}$ \\ ${ }^{1}$ Music Education Department, Faculty of Education, Uludag University, Bursa, Türkiye \\ Correspondence: Ajda Şenol Sakin, Music Education Department, Faculty of Education, Uludag University, \\ Bursa, Türkiye. Tel: 0090-505-8059362. E-mail: ajdasenol@gmail.com
}

Received: November 10, 2017 Accepted: November 14, $2017 \quad$ Online Published: December 20, 2017

doi:10.5539/hes.v8n1p1

URL: https://doi.org/10.5539/hes.v8n1p1

\begin{abstract}
Extended flute techniques, which are frequently found in contemporary flute literature, carry the flute to a different dimension, pushing the boundaries of composers and performers. Although the number of pieces containing these techniques in the world has increased rapidly, along with Turkish flute repertoire, written Turkish sources about extended flute techniques are limited to theses and articles. In this research, the use of extended flute techniques in flute education programmes in Turkey was investigated. A survey method was used in the research, and 20 teaching staff members participated in the survey by answering the questionnaire. As a result of the research, it was determined that 18 teaching staff members included extended flute techniques in their flute education programmes, and 2 teaching staff members did not use these techniques in flute education, particularly because "the techniques and pieces do not accord with the levels of the students" and because of "the difficulty of the pieces". In the conclusion, the difficulties faced by the teaching staff during training in extended flute techniques are summarized, and the suggestions of the teaching staff are mentioned.
\end{abstract}

Keywords: flute, extended flute techniques, flute education, contemporary pieces, Turkey

\section{Introduction}

Twentieth century social events, including the rapid development and change of art movements, have led composers to new experiments. The extended techniques in the instruments that came out with the search for different timbers have developed in the flute as well. The flute has rapidly become a multi-coloured and technically developed instrument (Önertürk, 2015a:1). The most commonly used extended flute techniques are: "singing while playing or simultaneous singing and playing, multiphonics, harmonics, key percussion, alternative fingers, flutter tongue, whistle tones, glissando, microtonal, etc." (Ataman, 2016; Önertürk, 2015a; Pietersen, 2010; Seçkin, 2011).

Extended flute techniques that allow a flute to be a polyphonic instrument are singing while playing or simultaneous singing and playing, and multiphonics. Thanks to these techniques, which were spearheaded by Jazz musicians and developed by composers, the flute not only responds to new sound searches but also becomes a polyphonic instrument (Gray, 2006:2). In addition to these techniques, some extended flute techniques are microtonal, allowing microtones to be played with the flute, and for different sound colours to be produced through alternative fingers, flutter tongue and whistle tone techniques ${ }^{1}$.

With the development of extended techniques, there have also been changes in musical notation. Composers

${ }^{1}$ For more information about extended flute techniques, these resources can be examined:

Dick, R. (1975). The Other Flute. A Performance Manual of Contemporary Techniques. England: Oxford Univesity Press

Moorhead, KE. (2012). A Performer's Perspective on the Evolution and Realisation of Extended Flute Techniques: A Portfolio of Recorded Performances and Exegesis, PhD Thesis, Adelaide University Elder Conservatory.

Pietersen, IK. (2010). A Structured Teaching Approach to Extended Flute Techniques at Pre-Tertiary Level. Master Thesis. Faculty of Humanities University of Cape Town.

Wette-Smith, B. (1978). Sound Modification Techniques in Selected Fluted Repertoire since 1966 Volume I. PhD Thesis. Rochester University. 
often offer explanations about the new notation at the beginning of their partitions. However, sometimes this new notation can be difficult for the performers. This free notation is based not on a single rule but on everyone's own way of notating their personality (Seçkin, 2011:14).

In Turkey, professional flute education is given in conservatories, music education department, music departments, military band schools and fine arts high schools. The contents of the comprehensive curriculum of the flute courses in these sections are prepared by the teaching staff, taking into account the level of the student. Despite the increase in the number of pieces including extended flute techniques both in Turkish flute repertoire and international flute repertoire, written Turkish etudes, exercises, and resources utilizing these techniques are very few. This situation raises the following questions:

(1) Do extended flute techniques occur in flute education in Turkey?

(2) At which level are extended flute techniques taught in Turkey?

(3) Which pieces including extended flute techniques are being used in flute education in Turkey?

(4) What are the opinions of the teaching staff about extended flute techniques?

\section{Method}

This research was carried out using a field survey method to determine the use of extended flute techniques in flute education in Turkey.

Ten questions were asked in the sample group to determine the use of extended flute techniques in flute education in Turkey. The first two questions of the questionnaire asked teaching staff which institutions they work in and what their titles are.

A questionnaire was prepared for this research. Theses and articles about this subject were examined. Of the 10 questions prepared, 8 questions were multiple choices, the last two of which were open-ended. The "other" option and description field were added to the answers of the required questions. Thus, if the teaching staff member has different thoughts, it is aimed to determine them. While the extended flute techniques in the questionnaire were determined Önertürk's article (2015a) "Analysis of the Flute Techniques in the 20th Century Music with Suggestions to the Flutists and Composer" and Ataman's article (2016) "The Polyphony Techniques in Flute Teaching” and Seçkin's master thesis (2011) “After 1950s Flute Music and Special Effects” was used. In addition, the pieces that could be taken as examples for the question "What are the pieces containing extended flute techniques in your flute education programmes?" were prepared from the article titled "The Leading Pieces of the 20th Century Flute Music Repertoire" by Önertürk (2015b) and the experiences of the researcher.

The questionnaire was prepared online via Microsoft Word and the SurveyMonkey website. The questionnaire was applied face-to-face with some teaching staff, and it was sent by e-mail to the other teaching staff. All answered questionnaires were entered into the system on the online survey site, and all the data were provided together.

In the research, multiple choice questions were analysed by percentage and frequency methods, and open-ended questions were analysed by descriptive analysis methods.

\subsection{Participants}

The universe of the research consists of teaching staff working in state conservatories, music education department, music departments and fine arts high schools in Turkey. The research sample group comprised 20 teaching staff members participating in the survey $(n=20)$. Personal details of the teaching staff are shown in Table 1. 
Table 1. The personal details of the sample group

\begin{tabular}{lcc}
\hline Variables & n & \% \\
\hline Department & & \\
\hline Conservatory & 7 & 35 \\
Music Education Department & 6 & 30 \\
Music Department & 3 & 15 \\
Fine Arts High School & 4 & 20 \\
\hline Title & & \\
\hline Professor & 2 & 10 \\
Associate Professor & 4 & 20 \\
Assistant Professor & 4 & 20 \\
Lecturer & 2 & 10 \\
Expert & 1 & 5 \\
Research Assistant & 2 & 10 \\
Teaching Staff (Part time) & 1 & 5 \\
Teacher & 4 & 20 \\
\hline Total & $\mathbf{2 0}$ & $\mathbf{1 0 0}$ \\
\hline
\end{tabular}

According to Table 1, from the sample group, 7 teaching staff are working in a conservatory, 6 are working in music education department, 4 are working in fine arts high school and 3 are working in a music department. More teaching staff were asked to respond to the questionnaire. However, some teaching staff stated that they could not take time because of work intensity, and some teaching staff did not provide any justification detailing their reasons for not responding to the questionnaire. As seen in Table 1, 2 professors, 4 associate professors, 4 assistant professors, 2 lecturers, 1 expert, 2 research assistants, 1 part time teaching staff member and 4 teachers participated in the research.

\section{Results}

To determine the use of extended flute techniques in flute education in Turkey, the teaching staff were asked "Do you use extended flute techniques and pieces that were composed with these techniques in your flute education programmes?" The subsequent responses of the teaching staff are shown in Table 2.

Table 2. The use of extended flute techniques in flute education programmes by teaching staff

\begin{tabular}{lcc}
\hline & $\mathbf{n}$ & $\mathbf{\%}$ \\
\hline Yes & 18 & 90 \\
No & 2 & 10 \\
\hline Total & $\mathbf{2 0}$ & $\mathbf{1 0 0}$ \\
\hline
\end{tabular}

Table 2 shows that 18 teaching staff members answered yes to question and 2 answered no.

The teaching staff members were asked "Why don't you use extended flute techniques in your flute education programme?" The responses of the teaching staff are shown in Table 3.

Table 3. Teaching staff members' reasons for not including extended flute techniques in flute education programmes

\begin{tabular}{lll}
\hline & $\mathbf{n}$ \\
\hline (1) & Difficulty of pieces & 2 \\
(2) & Few written sources about extended flute techniques in Turkish & 2 \\
(3) & Few written exercises method about extended flute techniques in Turkish & 2 \\
(4) & Techniques and pieces do not accordance the level of students & 2 \\
(5) & I do not recognize pieces & 2 \\
(6) & I do not recognize extended flute techniques or I recognize a little & 2 \\
(7) & The difficulty of correct expression (playing) of extended flute techniques & 2 \\
(8) & Priority of students to learn basic techniques first & 1 \\
(9) Not requested this kind of music in Turkey & 1 \\
\hline
\end{tabular}

This question was posed to teaching staff in multiple choice format. The 8th and 9th reasons in the table were 
added by the teaching staff. In addition, the other choices given to the teaching staff were "limited access the sheet music of the pieces", "less printed copies of sheet music of the pieces" and "sheet music of the pieces not sold in Turkey". However, none of the teaching staff marked these choices.

Extended flute techniques used by the teaching staff in the flute education programmes and the periods during which they use these techniques are shown in Table 4.

Table 4. Extended flute techniques used by the teaching staff in the flute education programmes and the periods during which they use these techniques.

\begin{tabular}{llllllllll}
\hline & \multicolumn{3}{l}{ High School } & \multicolumn{2}{l}{ Undergraduate } & \multicolumn{2}{l}{ Master's } & Ph. D./ D.M.A & Total \\
\cline { 2 - 7 } & $\mathrm{n}$ & $\%$ & $\mathrm{n}$ & $\%$ & $\mathrm{n}$ & $\%$ & $\mathrm{n}$ & $\%$ & Respondent (n) \\
\hline Harmonics & 7 & 43,75 & 11 & 68,75 & 5 & 31,25 & 4 & 25 & 16 \\
Alternative fingers & 5 & 35,71 & 10 & 71,43 & 4 & 28,57 & 4 & 28,57 & 14 \\
Tone colour & 4 & 33,33 & 10 & 83,33 & 4 & 33,33 & 4 & 33,33 & 12 \\
Timbral trills & 4 & 50 & 6 & 62,50 & 3 & 37,50 & 3 & 37,50 & 8 \\
Whistle tones & 3 & 30 & 6 & 60 & 4 & 40 & 3 & 30 & 10 \\
Whisper tones & 1 & 11,11 & 6 & 11,67 & 5 & 55,55 & 3 & 33,33 & 9 \\
Blowing and breathing & 3 & 30 & 5 & 50 & 4 & 40 & 3 & 30 & 10 \\
into the flute & 0 & 0 & 2 & 33,33 & 4 & 66,67 & 2 & 33,33 & 6 \\
Trumpet voice & 6 & 42,86 & 9 & 64,29 & 5 & 35,71 & 3 & 21,43 & 14 \\
Glissando & 3 & 30 & 6 & 60 & 3 & 30 & 5 & 50 & 10 \\
Microtonal & & & & & & & & & \\
Singing while & 2 & 15,38 & 7 & 53,85 & 6 & 46,15 & 3 & 23,08 & 13 \\
playing/Simultaneous & & & & & & & & & \\
singing and playing & & 12,50 & 5 & 62,50 & 5 & 62,50 & 4 & 50 & 8 \\
Multiphonics & 4 & 40 & 4 & 40 & 5 & 50 & 4 & 40 & 10 \\
Key percussion & 1 & 12,50 & 3 & 37,50 & 5 & 62,50 & 3 & 37,50 & 8 \\
Percussive Effects & 7 & 41,18 & 13 & 76,47 & 4 & 23,53 & 3 & 17,65 & 17 \\
Flutter tongue & 3 & 33,33 & 7 & 77,78 & 4 & 44,44 & 3 & 33,33 & 9 \\
Pizzicato & 3 & 42,86 & 2 & 28,57 & 4 & 54,14 & 3 & 42,86 & 7 \\
Speaking an playing & 1 & 14,29 & 2 & 28,57 & 3 & 42,86 & 5 & 71,43 & 7 \\
Noise sounds & 0 & 0 & 2 & 33,33 & 4 & 66,67 & 4 & 66,67 & 6 \\
Jet whistle & 2 & 28,57 & 1 & 14,29 & 3 & 42,86 & 6 & 85,71 & 7 \\
Circular Breathing & & & & & & & & & \\
\hline
\end{tabular}

According to Table 4, the most used extended flute techniques of the teaching staff are flutter tongue $(\mathrm{n}=17)$, harmonics $(\mathrm{n}=16)$, alternative fingers $(\mathrm{n}=14)$ and glissando $(\mathrm{n}=14)$. Table 4 also shows that trumpet voice and jet whistle are not used in high school education.

The teaching staff were asked "How do you decide which extended flute techniques to teach in flute education programmes?" (See Table 5). Four answer choices were provided for this question, and the "other" option was added to allow the possibility of alternative responses. Teaching staff were able to mark more than one response for this question.

Table 5. The answer to the question "How do you decided which extended flute techniques to teach in flute education programmes?"

\begin{tabular}{lcc}
\hline & $\mathbf{n}$ & $\mathbf{\%}$ \\
\hline I teach the techniques involved in the pieces & 11 & 61,11 \\
I teach the techniques appropriate to the level & 9 & 50 \\
of the student and I choose pieces utilizing these techniques & - & - \\
I teach the techniques at the same time & 2 & 11,11 \\
I determine different techniques for each class/period or level & 1 & 5,55 \\
\hline
\end{tabular}

According to Table 5, it was determined that 11 teaching staff members teach the extended flute techniques which occur in the pieces, 9 teaching staff members choose the techniques appropriate to the student's level, 2 teaching staff members determine different techniques for each level, and 1 teaching staff member chooses 
extended flute techniques that can help the problems of the student.

Teaching staff members were asked "What are the pieces containing extended flute techniques in your flute education programmes, and at what period do you study these pieces with your students?" For this question, L. Berio's, B. Ferneyhough's, E. Varése's, A. Jolivet's, K. Fukushima's and M. Doğuduyal's pieces were given in terms of creating samples. In addition, an "other" response option was added.

Table 6. Pieces containing extended flute techniques used by the teaching staff in flute education programmes

\begin{tabular}{lcccc}
\hline \multirow{2}{*}{ Name of Piece } & High School & Undergraduate & Master's & Ph. D./ D.M.A \\
\cline { 2 - 5 } & $\mathbf{n}$ & $\mathbf{n}$ & $\mathbf{n}$ & $\mathbf{n}$ \\
\hline L. Berio - Sequenza I & - & 4 & 2 & 1 \\
B. Ferneyhough - Cassandra's Dream Song & - & 1 & 2 & 1 \\
E. Varése - Density 21.5 & 2 & 4 & 2 & 2 \\
A. Jolivet - Incantations for solo flute & 1 & 4 & 2 & 2 \\
K. Fukushima - Mei & 2 & 4 & 2 & 1 \\
M. Doğuduyal - The Mouldy Existence & 1 & - & 3 & - \\
Other: Turkish Music Pieces with microtones & 1 & 1 & - & - \\
Other: N. Rimsky-Korsakov- & - & 1 & - & - \\
Flight of the Bumblebee & - & 1 & - & - \\
Other: A.Piazzola -Night Club 1960 & - & 1 & 1 & - \\
Other: A. Jolivet - Flute Concerto & - & 1 & 1 & - \\
Other: A. Jolivet - Chant de Linos & - & - & - & - \\
Other: Fikret Amirov & & & & \\
\hline
\end{tabular}

The pieces containing the extended flute techniques that the teaching staff included in the flute education programmes are listed in Table 6. According to Table 6, L. Berio's Sequenza I is studied in flute education programmes at the undergraduate $(n=4)$, master's $(n=2)$ and Ph.D./D.M.A $(n=1)$ levels. B. Ferneyhough's Cassandra's Dream Song is studied in flute education programmes at the undergraduate $(\mathrm{n}=1)$, master's $(\mathrm{n}=2)$ and Ph.D./D.M.A ( $\mathrm{n}=1)$ levels. E. Varése's Density 21.5 is studied in flute education programmes at the high school $(n=2)$, undergraduate $(n=4)$, master's $(n=2)$ and Ph.D./D.M.A $(n=2)$ levels. A. Jolivet's Incantations for solo flute is studied in flute education programmes at the high school $(n=1)$, undergraduate $(n=4)$, master's $(n=2)$ and Ph.D./D.M.A (n=2) levels. K. Fukushima's $\mathrm{Mei}$ is studied in flute education programme at the high school $(\mathrm{n}=2)$, undergraduate $(\mathrm{n}=4)$, master's $(\mathrm{n}=2)$ and Ph.D./D.M.A $(\mathrm{n}=1)$ levels. M. Doğuduyal's The Mouldy Existence is studied in programmes at the high school $(\mathrm{n}=1)$ and master's $(\mathrm{n}=1)$ levels. In addition to these pieces, there are some pieces not included in the list but added by the teaching staff. A. Jolivet's Flute Concerto and Chant de Linos are studied at the undergraduate and master's levels. N. Rimsky-Korsakov's Flight of the Bumblebee and Piazzola's Night Club 1960 are studied at the undergraduate level. Moreover, 1 teaching staff member stated that s/he practised Turkish Music, which includes microtones, at the high school and undergraduate levels with her/his students. Another teaching staff member responded that "I practice Fikret Amirov's pieces with my student".

Teaching staff members were asked about the difficulties they faced in teaching extended flute techniques, and 13 options were offered. In case of alternative responses, the other option was added. Teaching staff members were able to mark more than one choice.

${ }^{2}$ Teaching staff who said s/he taught Fikret Amirov's pieces did not specify the period. 
Table 7. Difficulties faced by teaching staff in training extended flute techniques.

\begin{tabular}{|c|c|c|c|}
\hline & & n & $\%$ \\
\hline (1) & Difficulty of pieces & 7 & 43,75 \\
\hline (2) & Few written pieces with extended flute techniques & 3 & 18,75 \\
\hline (3) & Pieces are less recognizable & 8 & 50 \\
\hline (4) & Pieces use multiple extended flute techniques at the same time & 3 & 18,75 \\
\hline (5) & Unable to obtain the sheet music for the pieces & 2 & 12,50 \\
\hline (6) & Insufficient printed sheet music for pieces & - & - \\
\hline (7) & Sheet music of the pieces are not sold in Turkey & - & - \\
\hline (8) & Few written sources about extended flute techniques in Turkish & 9 & 56,25 \\
\hline (9) & Few written exercise methods for extended flute techniques in Turkish & 6 & 37,50 \\
\hline (10) & Techniques and pieces are not appropriate for the level of students & 6 & 37,50 \\
\hline (11) & I do not recognize extended flute techniques or I recognize only a little & 5 & 31,25 \\
\hline (12) & Difficulty in the correct expression (playing) of extended flute techniques & 9 & 56,25 \\
\hline (13) & Students' flutes are not suitable for playing with these techniques & 5 & 31,25 \\
\hline (14) & Other: I teach if the student is interested and if the piece is appropriate & 1 & 6,25 \\
\hline
\end{tabular}

Table 7 shows that the most common, difficulties that the teaching staff face are "few written sources about extended flute techniques in Turkish" $(n=9)$ and "difficulty in the correct expression (playing) of extended flute techniques" ( $n=9)$. Additionally, other difficulties faced by the teaching staff are "pieces are less recognizable" $(n=8)$ and "difficulty of pieces" $(n=7)$. In addition, none of the teaching staff face difficulties involving "insufficient printed sheet music for pieces" and "sheet music is not sold in Turkey".

Teaching staff members were asked "Why do you use extended flute techniques and pieces in your flute education programmes?" Teaching staff members' answers were analysed with the following subheadings: "in terms of performance development", "need for modernization" and "as these pieces are included in international competitions" (See Figure 1).

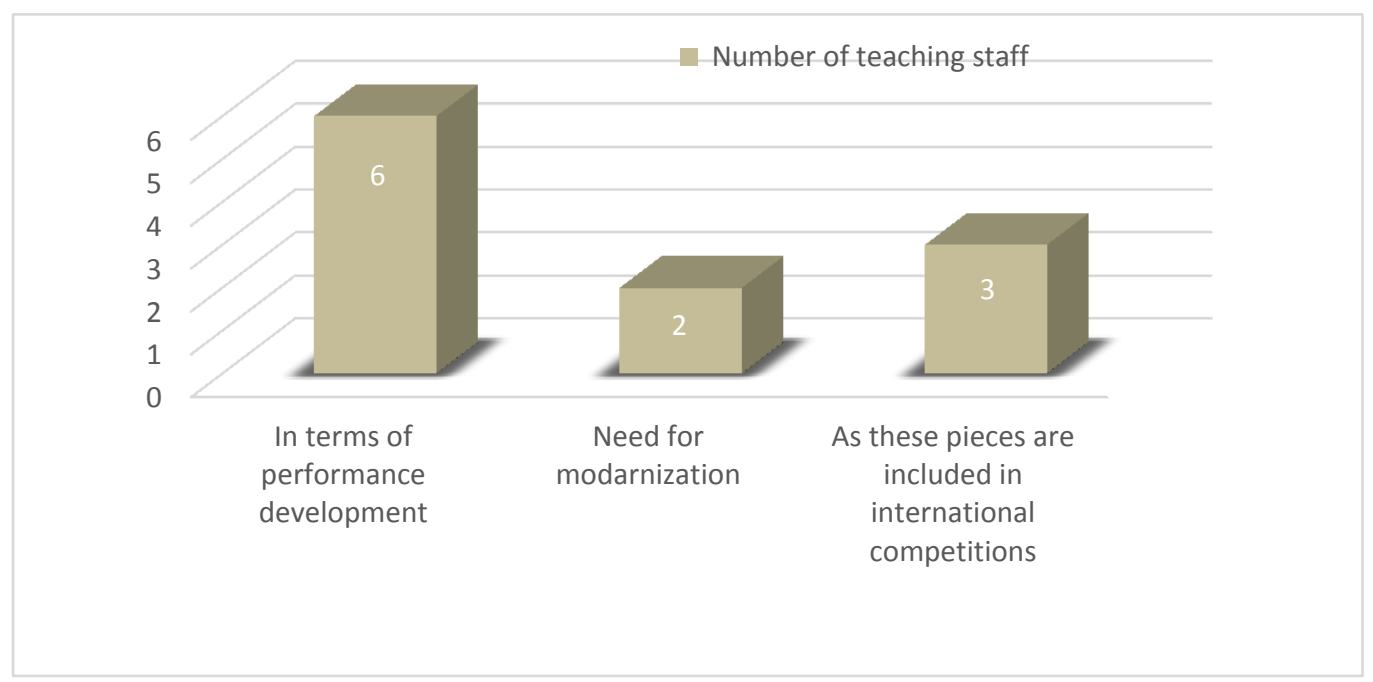

Figure 1. Reasons that the teaching staff members included extended flute techniques in flute programmes

In addition, the views of the teaching staff on student achievement of extended flute techniques in flute education programmes are as follows:

"I think that students will be able to improve individual studying times by studying extended flute techniques, and it will bring performance success to being in search of new colour (sound)" (P1). "In flute training, using extended flute techniques is very important and necessary. This technical study supports the further development of the technical level by giving the student flexibility" (P3).

The views of teaching staff about which extended flute techniques should be taught at which levels are as follows: 
"The teaching of extended flute techniques must be started from an early age" (P8). "There are extended techniques and pieces that can be taught at every level. Students should not be expected to be at a very advanced level to teach them extended flute techniques" (P12). "Very few students can succeed extended flute techniques after the basic blowing techniques have been taught" (P11).

The other opinions and suggestions of teaching staff about extended flute techniques are as follows:

"It is necessary to reproduce the written, visual and audio sources that can be reached by educators who have little or no knowledge of extended flute techniques" (P2). "For the purpose of the prevalence of repertoire and the prevention of alienation, more courses, festivals and youth orchestra projects involving extended techniques should be organized. When the necessary conditions are met, the structure and aesthetic knowledge of this (new) music should be added to the undergraduate programmes" (P4). "We need Turkish written sources. Turkish resources prepared by experts and workshops in this regard are needed." (P5). "Teaching staff members should be more trained in this regard. It is necessary to increase the number of etudes and pieces containing simple extended flute techniques" (P6). "To teach extended flute techniques, it is necessary to know flute techniques up to the finest details. For this reason, many etudes about these techniques should be systematically studied/played" (P9). "Teaching staff members need to be more equipped with new music (extended techniques) and should perform this music correctly. Afterwards, the pieces containing these techniques should be placed in their repertoire" (P10). "More sources are needed for contemporary music and extended flute techniques. Masterclasses and workshops must be available, and their number should be increased" (P13).

\section{Conclusion}

When research findings are examined, it is seen that 20 teaching staff members participated in the research. It was determined that 18 of these teaching staff members included extended flute techniques in flute education programmes, and 2 teaching staff members did not use these techniques.

One of the reasons that some teaching staff members do not use extended flute techniques in flute education programmes is "the techniques and pieces are not appropriate for the levels of the students". Borkowski (2008) also referred to a similar topic in his doctoral thesis. "The lack of new music studied in university programmes lies in the complexity and difficulty of the repertoire. Complex works are seldom played" (Borkowski, 2008:2).

From the responses of teaching staff members who used extended flute techniques in flute education programmes, it was determined that the most commonly used extended flute techniques are flutter tongue, harmonics, alternative fingers and glissando. While the teaching staff members usually teach the techniques involved in the pieces, 9 teaching staff members said that they taught the techniques appropriate to the level of the student, and they chose pieces containing these techniques.

The problems faced by the teaching staff in extended flute education can be summarized as follows from highest to lowest frequency:

- Few written sources about extended flute techniques in Turkish

- The difficulty of correct expression (playing) of extended flute techniques

- Pieces are less recognizable

- Difficulty of pieces

- Few written exercise methods for extended flute techniques in Turkish

- Techniques and pieces do not accord with the level of students

- I do not recognize extended flute techniques, or I recognize only a little

- Students' flutes are not suitable for playing with these techniques

- Few written pieces with extended flute techniques

- Pieces using multiple extended flute techniques at the same time

- Unable to obtain the sheet music for the pieces

When the answers of the teaching staff are examined, the reasons for including extended flute techniques in flute education programme can be summarized as follow: (1) performance development, (2) inclusion of pieces containing extended flute techniques in international competitions, and (3) need to modernize.

According to the research, the suggestions given by the teaching staff about extended flute techniques are as follows:

- It is necessary to reproduce the written, visual and audio sources of extended flute techniques,

- More courses, workshop, masterclasses, festivals and youth orchestra projects involving extended techniques should be organized,

- New music (extended techniques) should be added to the flute education programmes, 
- Turkish resources and books prepared by experts should be reproduced,

- Teaching staff should be more highly trained in this regard,

- Increasing the number of etudes, exercises, and pieces containing not only complex extended flute techniques but also simple techniques.

Additionally, it is recommended that students should be encouraged to play extended flute techniques by composing simple pieces to reinforce these techniques after preparation of exercises and etudes aimed only at the related technique, which is composed of simple to complex extended flute techniques and collaborated on by composers and flute instructors.

\section{Acknowledgements}

This article has been edited by American Journal Experts.

\section{References}

Ataman, ÖG. (2016). The Polyphony Techniques in Flute Teaching, Fine Arts (NWSAFA), 11(2), 54-65. https://doi.org/10.12739/NWSA.2016.11.2.D0173

Borkowski, JA. (2008). From Simple to Complex: Extended Techniques in Flute Literature; Incentive to Integrate Cognitive and Kinesthetic Awareness in University Programs. (Unpublished doctoral dissertation). Universitat für Music und darstellende Kunst Graz, Austria.

Dick, R. (1975). The Other Flute. A Performance Manual of Contemporary Techniques. England:Oxford Univesity Press. Retrieved January 27, 2017, from https://drive.google.com/file/d/0ByXT8veODB_TTEJ1Q3NnN3JtWlU/view

Gray, P. (2006). Extended Techniques for flute: Polyphonic Techniques - John McMurtey. Retrieved January 27, 2017, from https://cnx.org/contents/n01_OIG1@1/Extended-Techniques-for-Flute-

Moorhead, KE. (2012). A Performer's Perspective on the Evolution and Realisation of Extended Flute Techniques: A Portfolio of Recorded Performances and Exegesis, (Unpublished doctoral dissertation). Adelaide University Elder Conservatory, Australia.

Önertürk, C. (2015a). Analysis of the Flute Techniques in the 20th Century Music With Suggestions to the Flutists and Composer, Akademik Müzik Araştırmaları Dergisi, 1, 1-18. https://doi.org/10.5578/AMRJ.8920

Önertürk, C. (2015b). The Leading Pieces of the $20^{\text {th }}$ Century Flute Music Repertoire, Akademik Müzik Araştırmaları Dergisi, 2, 1-14.

Retrieved January 27, 2017, from http://dergipark.ulakbim.gov.tr/amader/article/view/5000134320/5000123135

Pietersen, IK. (2010). A Structured Teaching Approach to Extended Flute Techniques at Pre-Tertiary Level. (Unpublished master's thesis). Faculty of Humanities University of Cape Town, South Africa.

Seçkin, ME. (2011). After 1950's Flute Music and Special Effects. (Unpublished master's thesis). Dokuz Eylül University State Conservatory, İzmir, Turkey.

Wette-Smith, B. (1978). Sound Modification Techniques in Selected Flute Repertoire since 1966 Volume I. (Unpublished doctoral dissertation). Rochester University, New York, USA.

\section{Copyrights}

Copyright for this article is retained by the author(s), with first publication rights granted to the journal.

This is an open-access article distributed under the terms and conditions of the Creative Commons Attribution license (http://creativecommons.org/licenses/by/4.0/). 